\section{Benign Esophagorespiratory Fistula Complicated by Deep Impaction of Stent Mesh in the Esophageal Wall}

The placement of self-expandable metallic stents is widely accepted as a treatment for malignant esophagorespiratory fistulas [1-2]. In contrast, there is ongoing discussion about the use of metallic stents for temporary treatment of benign and potentially reversible esophageal disorders, because after only a few weeks stent retrieval may already be difficult [2-4].

We report on a rare case in which the endoscopic removal of three metallic stents, which had been in situ for more than 3 years for benign esophagorespiratory fistula, was actually impossible due to deep impaction of the stent mesh into the esophageal wall, and subtotal esophageal resection was thus required.

In January 2001, a 73-year-old-man in a reduced physical condition (56 kg, $168 \mathrm{~cm}$, BMI 19) presented with an express desire for treatment of a large esophagorespiratory fistula that had developed more than 3 years earlier, secondary to mediastinal hematoma and local inflammation after therapy with streptokinase for myocardial infarction (Figure $\mathbf{1}$ ). A total of three metallic stents (one Flamingo-Wallstent, one Ultraflex stent, one Gianturco-Z stent) had been placed in the esophagus to cover the fistula, with only temporary success, however, because of stent migration and dislocation. Since nutrition via a percutaneous endoscopic gastrostomy (PEG) had led to repeated aspiration, the patient had been fed exclusively by parenteral means for almost 3 years.

At admission in January 2001, endoscopy and bronchoscopy showed stents deeply embedded in the esophagus with several wires perforating into the trachea. Thus, endoscopic stent retrieval, even in a piecemeal fashion, was impossible.

Therefore, as a first operation transthoracic esophagectomy with cervical esophagostomy had to be performed to allow closure of the defect in the trachea (Figure

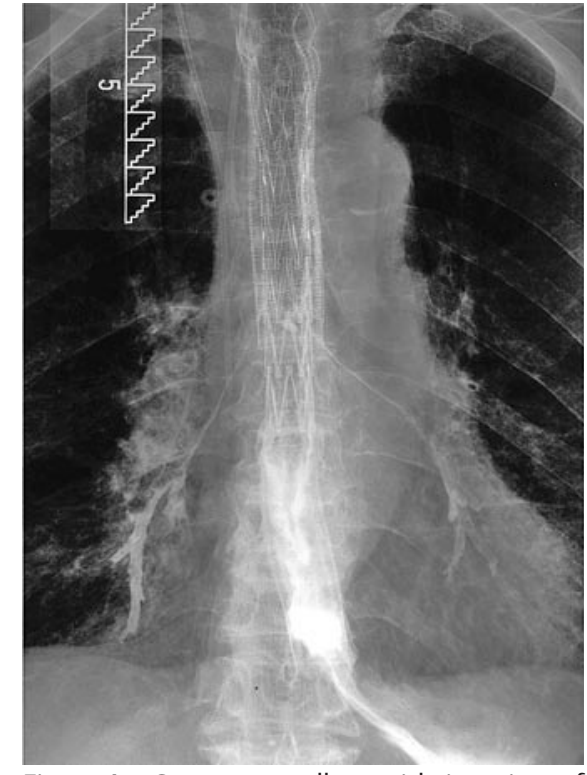

Figure 1 Contrast swallow with imaging of left and right bronchial tree indicating an esophagorespiratory fistula.

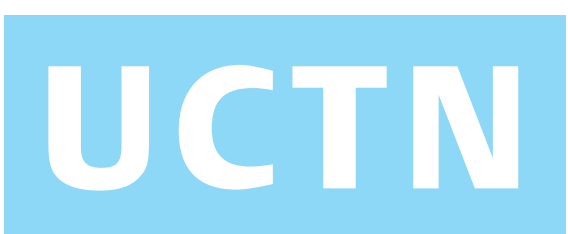

2a,b). During this operation, several wires had to be removed from of the trachea, lung and mediastinum. The postoperative course was complicated by recurrent pneumonias requiring mechanical ventilation for almost 3 months. At 1 year after esophagectomy, reconstruction was achieved with a cervical esophagogastric anastomosis via the retrosternal route. The patient is now in good physical condition, at 2 years after this operation, and on completely enteral nutrition.

\section{Acknowledgment}

The case described here was presented during the 24th Congress of the German Society for Endoscopy and Imaging Procedures, Munich, March 2004, and accord-

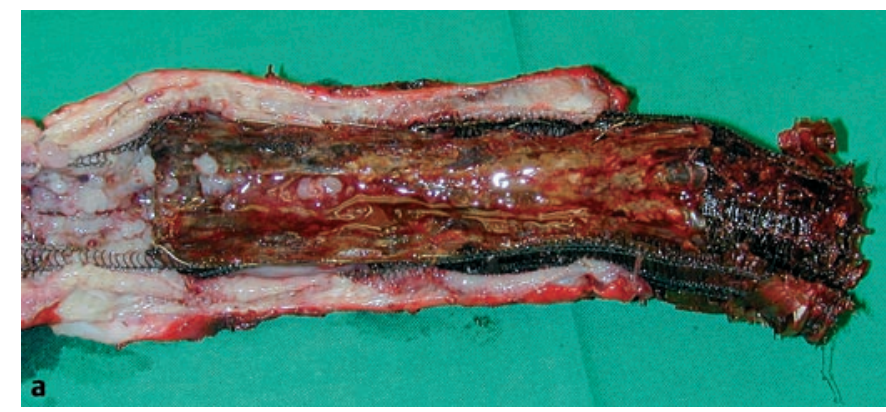

Figure $\mathbf{2}$ a, b Resected esophagus with stents deeply embedded in the esophageal wall.

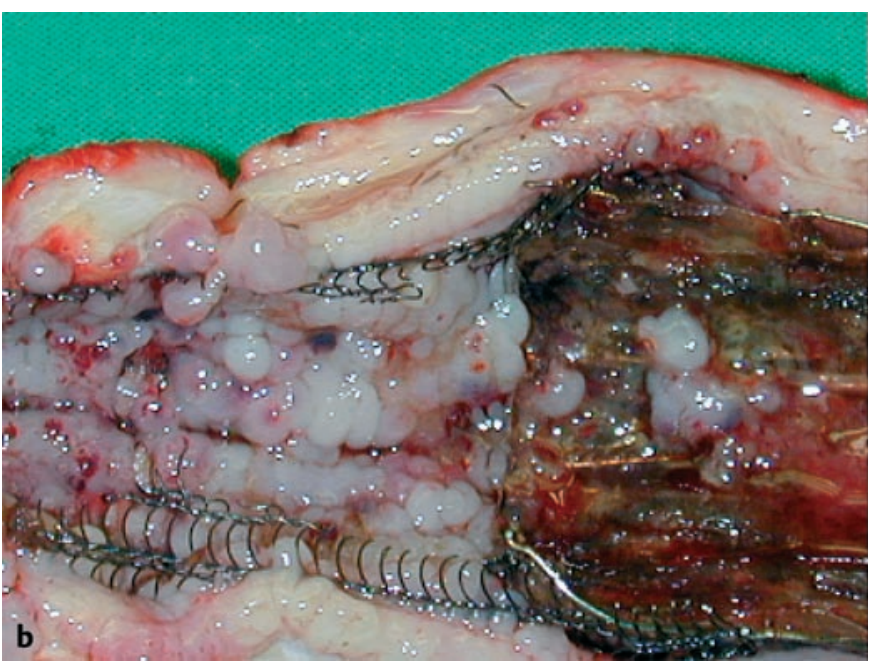


ingly reported in abstract form in Endos- References kopie Heute.

H. Lang ${ }^{1}$, G. C. Sotiropoulos ${ }^{1}$, F. H. Saner ${ }^{1}$, N. R. Frühauf ${ }^{1}$, K. Radecke ${ }^{2}$, W. Niebel ${ }^{1}$, C. E. Broelsch ${ }^{1}$

${ }^{1}$ Klinik für Allgemein- und Transplantationschirurgie, Universitätsklinikum Essen, Germany

${ }^{2}$ Klinik für Gastroenterologie und Hepatologie, Universitätsklinikum Essen, Germany.
${ }^{1}$ May A, Ell C. Palliative treatment of malignant esophagorespiratory fistulas with Gianturco-Z stents. A prospective clinical trial and review of the literature on covered metal stents. Am J Gastroenterol 1998; 93: 532-535

${ }^{2}$ Rösch T. Metallstents in der Gastroenterologie. Chirurg 1999; 70: 868-875

${ }^{3}$ Siersema PD, Homs MYV, Haringsma Jet al. Use of large-diameter metallic stents to seal traumatic non-malignant perforations of the esophagus. Gastrointest Endosc 2003; 58: $356-361$

${ }^{4}$ Ackroyd R, Watson DI, Devitt PG, Jamieson GG. Expandable metallic stents should not be used in the treatment of benign esophageal strictures. J Gastroenterol Hepatol 2001; 16: 484-487
Corresponding Author

Prof. Dr. H. Lang, MD

Klinik für Allgemein- und Transplantationschirurgie Hufelandstraße 55

45122 Essen

Germany

Fax: + 49-201-7231113

E-mail: hauke.lang@uni-essen.de 